\title{
FAMÍLIA CONTEMPORÂNEA E A AUSÊNCIA DE PRIVACIDADE: UM ESTUDO SOBRE A EXPOSIÇÃO DE ADOLESCENTES NAS REDES SOCIAIS
}

\section{CONTEMPORARY FAMILY AND THE ABSENCE OF PRIVACY: A STUDY ON THE TEENAGERS EXPOSURE ON SOCIAL NETWORKS}

\author{
Raissa Barquete Caramanico (Psicologia - UEL/raissa.rbc@gmail.com) \\ Prof. Dr. Paulo Roberto Carvalho (Orientador)
}

\section{RESUMO}

A instituição familiar foi primeiramente caracterizada pelo fechamento em si, por ser responsável pela divisão entre o que é privado e o que é público, e pela proteção das crianças. Contudo, devido a vários fatores que atravessaram esse núcleo, como a introdução da escola na vida dos filhos, o surgimento das mídias eletrônicas e da confissão, a barreira que envolvia a família foi se afrouxando, e os papéis familiares foram perdendo seu poder. Um dos movimentos que exemplifica essa ruptura pode ser visto atualmente através da exposição dos adolescentes nas redes sociais, que por vontade própria, rompem a divisão entre o íntimo e o público, e postam fotos sexualizadas na internet. Dentro do contexto em que ocorre, capitalista e pós-moderno, esse fenômeno pode ser entendido como decorrência das manobras do biopoder, que visa se encarregar da vida dos indivíduos, tendo acesso a todas suas particularidades e objetivando seu controle. Hoje, o adolescente aceita seu corpo sexualizado (como aprendeu na escola), toma posse disso e o expõe (como deseja o biopoder) por ter aprendido a confessar suas intimidades (com o psicólogo).

Palavras-chave: Família, adolescência, mídia e biopoder

\begin{abstract}
The family institution was first characterized by the closure in itself, to be responsible for the division between what is private and what is public and by the protection of their children. However, due to several factors that have gone through this core, as the school is brought into the lives of their children, the emergence of electronic media and confession, the barrier that surrounded the family was loosening, and family roles were losing their power. One of the movements that exemplifies this disruption can be seen today through the exposure of adolescents in social networks, which decides by itself to break the division between the intimate and the public, and post sexualized photos on the internet. Within the context in which it occurs, capitalist and post-modern, this phenomenon can be understood as a result of biopower maneuvers, which seeks to take care of people's lives, having access to all its peculiarities and aiming its control. Today, the teenager accepted his sexualized body (as learned in school), takes possession and exposes it (as biopower want) because he has learned to confess their innermost (with the psychologist).
\end{abstract}

Key words: Family, adolescence, midia and biopower 


\section{SEMINÁRIO DE PESQUISA EM CIÊNCIAS HUMANAS - SEPECH \\ Humanidades, Estado e desafios didático-científicos \\ Londrina, 27 a 29 de julho de 2016}

\section{INTRODUÇÃO}

A família burguesa, nascida em meados do século XVIII, na Europa, era caracterizada principalmente pelo seu fechamento em si. Ou seja, a divisão entre aquilo que envolvia seus membros de maneira pública era separado do que dizia respeito à vida privada, que era resguardada e compartilhada apenas com seus membros. O mundo do trabalho era enfrentado com frieza e calculismo, enquanto a porção afetiva das relações interpessoais era exclusiva dos membros da família, e ocorria dentro das fronteiras do lar (REIS, 1994). Essa concepção de família é uma concepção moderna, bem diferente daquela aceita na Idade Média. Neste período, as crianças se misturavam aos adultos, e eram tidas como suficientemente maduras após um desmame tardio. Por volta dos sete anos, elas já eram integradas na comunidade dos homens, dividindo com eles o trabalho e participando de seus jogos. A vida era ministrada dentro do coletivo, em uma mistura de idades e classes sociais, não havendo espaço para a intimidade, ou um tempo reservado à solidão. Nesse período, a família possuía um objetivo bem específico: assegurar a transmissão da vida e dos bens, sem necessariamente se aprofundar na sensibilidade e nos afetos. Era uma família sem amor (ARIÈS, 1986).

Na Idade Média também podemos destacar a importância dada à aprendizagem, que seria a transmissão de conhecimentos práticos do dia a dia, obtidos através do próprio convívio prematuro em relação direta com os adultos. Assim, as crianças aprendiam desde cedo, na prática, como se portar e como atuar na vida em sociedade, convivendo com os adultos no coletivo. Essa entrega dos filhos muito cedo ao grupo afrouxava os laços entre os pais e suas crianças, de forma que a família acabava desempenhando um papel muito mais moral e social, que sentimental. Foi a partir do século XV que esse cenário começou a mudar, quando a sociedade se atentou à importância da educação. Diferentemente da aprendizagem, a educação e a escola apareceram para promover uma iniciação social, com uma passagem gradual, e não tão abrupta, do estado da infância para o adulto. Essa evolução supria uma necessidade de rigor moral, ao despertar uma preocupação em separar o mundo pueril do mundo sujo dos adultos, buscando preservar sua inocência primitiva, e treinar as crianças para resistirem às tentações da vida madura. $\mathrm{O}$ surgimento da escola também demarcou uma mudança no papel da família, que agora tinha seus membros mais próximos, e mais preocupados em preservar a criança (ARIÈS, 1986).

Como dito por Ariès: "Os progressos do sentimento da família seguem os progressos da vida privada, da intimidade doméstica. O sentimento da família não se desenvolve quando a casa está muito aberta para o exterior: ele exige um mínimo de segredo" (1986, p. 238). Essas mudanças puderam ser vistas de maneira concreta, por exemplo, através das alterações na arquitetura da casa de família, que agora contava com cômodos privados, ligados por um corredor de acesso, separados das áreas comuns, visando a intimidade, a discrição e o isolamento, bem como no convívio social. As conversas agora seguiam a ordem da conveniência, onde os assuntos domésticos, familiares ou muito pessoais eram preservados e evitados com pessoas "de fora" da família.

No entanto, é importante lembrar que a família não é algo natural ou biológico, mas sim uma instituição criada através das relações dos homens, constituindo-se de diferentes formas ao longo do tempo e de acordo com as necessidades do contexto. Dessa forma, possui uma representação social que acaba por orientar a conduta de seus 


\section{SEMINÁRIO DE PESQUISA EM CIÊNCIAS HUMANAS - SEPECH \\ Humanidades, Estado e desafios didático-científicos \\ Londrina, 27 a 29 de julho de 2016}

membros, exercendo também uma função ideológica que leva a uma reprodução social. Os pais, principais agentes da educação, ensinam que a família é algo natural e universal, com hierarquias de poder que devem ser aceitas e respeitadas, estabelecendo essa instituição como um importante aparelho ideológico, de reprodução de dominância e submissão. Marcuse (apud REIS, 1994) ao estudar as famílias capitalistas mais avançadas, destaca que as funções de seus membros encontram-se descentralizadas, o que ele acaba qualificando como uma forma aprimorada dos mecanismos de dominação:

Se a família burguesa dos períodos anteriores criava a submissão, criava também a revolta que se expressava no inconformismo e na luta contra o pai e a mãe, alvos facilmente identificáveis como agentes de dominação. Na civilização madura 'a dominação torna-se cada vez mais impessoal, objetiva, universal e também cada vez mais racional, eficaz e reprodutiva' (REIS, 1994, p. 103).

Desse modo, o que antes era de função exclusiva da família, passa agora a ser atravessado por uma grande rede de agentes sociais, que vão desde a escola até os aparelhos de comunicação em massa. A maneira primordial como a família organiza a vida emocional de seus membros é capaz de transformar a ideologia dominante em visão de mundo, fazendo-os assumir mais tarde seu código de conduta e valores. Isso faz com que eles aceitem as normas que já estavam estabelecidas antes deles nascerem, a serem submissos em relação a esses cruzamentos, pois aceitam o que é imposto sem questionar. É muito importante ressaltar esse ponto, principalmente num período de grande expansão do alcance da mídia. A televisão hoje, por exemplo, está presente na grande maioria dos lares, adentrando o espaço familiar, rompendo as distâncias culturais e oferecendo risco à padronização dos costumes e valores (REIS, 1994). Isso sem nem citar o rádio e a internet.

Postman (apud BUCKINGHAM, 2007) identifica na mídia um dos maiores "vilões" da infância. Segundo ele, a eliminação das brincadeiras tradicionais, do vestuário tipicamente infantil, o crescimento da homogeneização dos interesses de lazer, linguagem, hábitos alimentares e preferências seriam as causas do aumento na criminalidade infantil, consumo de drogas, atividades sexuais e gravidez na adolescência. Destaca também os usos de imagens eróticas de crianças em filmes e comerciais, bem como o predomínio de temas adultos na literatura infantil. Acredita que a imprensa teve papel importante, no sentido de ter incentivado a individualidade das pessoas, e o "senso de eu intensificado". Para Postman, a imprensa exigia a alfabetização como forma de acesso, o que acabou por incentivar a criação das escolas, que colocavam em cheque a "exuberância" da infância, e cultivavam a quietude, imobilidade, contemplação e regulação das funções corporais. Dessa forma, a maturidade passou a ter um efeito simbólico para além do biológico. Contudo, Postman reconhece que a imprensa tinha ao menos a habilidade de preservar certos assuntos do mundo "adulto" através da linguagem, impedindo a compreensão daqueles que não eram alfabetizados, coisa que a TV não fazia, sendo considerada um meio de exposição total. Postman defendia que a TV foi responsável por acabar com o sentimento da vergonha, qualidade que ele entendia como pré-requisito para a existência da infância. Enquanto a imprensa era considerada essencialmente simbólica e linear, cultivando a 


\section{SEMINÁRIO DE PESQUISA EM CIÊNCIAS HUMANAS - SEPECH \\ Humanidades, Estado e desafios didático-científicos \\ Londrina, 27 a 29 de julho de 2016}

abstração e o pensamento lógico, a TV já era um meio visual, e por isso não requereria nem cultivaria habilidades especiais para sua interpretação, bem como não se sujeitaria às regras da evidência ou da lógica, sendo essencialmente irracional.

Meyrowitz (apud BUKINGHAM, 2007), outro teórico sobre a infância, acredita que esta e a idade adulta estejam passando por um processo de fusão. Defende que a "criança" e a "psicologia da criança" são construções sociais que refletem valores culturais muito específicos, e que a noção de "inocência infantil" não é natural ou essencial, mas foi produzida para fazer a diferenciação social dos adultos e das crianças. Nesse sentido, Meyrowitz se preocupa menos com as implicações cognitivas das mídias, e mais com seus usos sociais. A imprensa ainda é capaz de segregar adultos e crianças através da alfabetização, porém a TV, por utilizar de formas simbólicas e imediatamente acessíveis, tende a reintegrá-la. Para além das mensagens que transmite, a TV modifica o padrão de fluxo de informação que entra nas casas, desafiando o controle dos adultos e permitindo que a criança tenha contato com interações que não são características de sua fase. Dessa forma, a TV mina as tentativas dos adultos de manter "sigilo". Controlar o acesso das crianças à mídia tende a ser difícil, e por isso, para Meyrowitz, se faz necessário que a prática do controle familiar, hoje em dia, se torne aberta e visível.

Contudo, é preciso ir para além do determinismo tecnológico. O confronto dual entre a imprensa - responsável pela criação e concepção contemporânea de infância - e a TV - aquela que está destruindo-a - coloca a tecnologia como algo autônomo em relação a outras forças sociais, como se fosse capaz de exercer sua influência independente dos contextos ou das finalidades para qual é utilizada. Carmen Luke (apud BUCKINGHAM, 2007) indicou que creditar a criação da infância à imprensa é uma simplificação no mínimo exagerada e determinista. Pelo contrário, a infância surgiu como resultado de um complexo entrelaçamento entre ideologia, governo, pedagogia e tecnologia, cada uma delas agindo de uma maneira, aplicando determinada força, consequentemente desenvolvendo-se de formas diferentes, e em diferentes níveis, dependendo do contexto social e cultural em que ocorriam. Além disso, as teorias de Postman dentre outros, entendem o público das mídias como uma massa homogênea, sendo as crianças, especificamente, caracterizadas como passivas e indefesas diante das manipulações. Dessa forma, o público, conclui-se, não seria socialmente diferenciado, nem capaz de responder criticamente ao que assiste.

Como proteger a criança e filtrar o conteúdo a que tem acesso na pósmodernidade? De acordo com as teorias aqui vistas, seria preciso desligar os aparelhos de televisão, os computadores, assim como parar os relógios. Propor tais ideias seria não reconhecer que o tempo dessas ações conservadoras já passou, reafirmando uma moralidade tradicional, estruturas familiares e papéis de gêneros hierárquicos, e formas convencionais de criação dos filhos. Propostas não aplicáveis nos dias atuais, onde o acesso às mídias é quase acidental e inevitável.

Outro ponto a ser considerado é que todas as propostas são direcionadas aos pais e responsáveis: os pais que devem proteger e controlar seus filhos, bem como ajuda-los a resistir à influência midiática. Isso reafirma a imagem passiva das crianças frente aos meios de comunicação e as tentativas adultas de controle e manipulação. Negando o papel ativo das crianças, e as colocando como vítimas passivas, fazem com que a tese da "morte da infância" caia em descrédito. 


\section{SEMINÁRIO DE PESQUISA EM CIÊNCIAS HUMANAS - SEPECH \\ Humanidades, Estado e desafios didático-científicos \\ Londrina, 27 a 29 de julho de 2016}

É importante entender que, hoje em dia, o acesso das crianças e adolescentes aos meios de comunicação não é mais intermediado pela ação de um adulto. As TVs e os rádios estão ligados em casa na ausência dos pais, nos restaurantes, nas escolas, enfim, nos espaços públicos, onde não é possível controlar quem tem acesso às informações transmitidas. Além disso, há também o fato da internet hoje ser mais amplamente acessível, através não só dos computadores, mas do celular, tablete, videogame, objetos que já fazem parte da rotina dos adolescentes pós-modernos. Em uma pesquisa realizada em 2012 pela ONG Safernet e pela empresa GVT com quase 3 mil jovens brasileiros, foi constatado que $62 \%$ dos entrevistados com idades entre 9 a 23 anos, entravam na internet diariamente, sendo que $80 \%$ deles o faziam com o objetivo de acessar as redes sociais. Outra pesquisa, também realizada em 2012, pelo Comitê Gestor de Internet no Brasil, apontou que mais de dois terços das crianças entrevistadas acreditam saber mais sobre a internet que seus pais e responsáveis, sendo que 53\% destes nem faziam uso da internet (GUZZI, 2013). Ou seja, negar o uso ativo das mídias eletrônicas pelas crianças e adolescentes hoje em dia seria muita ingenuidade e não lançar o olhar sobre esse novo movimento, não buscar compreendê-lo seria um tanto quanto perigoso.

Difundiu-se a tecnologia da informação, e o poder de se comunicar ou relacionar virtualmente com pessoas de todo o planeta foi a grande descoberta compartilhada tanto dentro quanto fora da família (Chaves e Luz, 2007 apud Spizzirri, 2008). Ao adolescente, nascido nesse período efervescente, filho de uma família pós-moderna, coube a tarefa de se inserir e adaptar a esse novo contexto, constituído de intensas transformações e criações de novos modos de pertencimento e relacionamento a todo momento. A cultura da informação globalizada e pós-moderna é caracterizada por seus traços exibicionistas que, influenciados pela mídia, inebriam os indivíduos, principalmente os adolescentes, a sentirem o equivalente a uma necessidade de visibilidade, fazendo a própria intimidade perder o seu valor particular. Sites de relacionamento como o Facebook e o fácil acesso à aplicativos que difundem materiais virtuais com rapidez (Whatsapp, Snapchat, Instagram) surgem como meios de suprir essa demanda por exposição e o rompimento do espaço privado. Apesar de serem dispositivos que permitem a comunicação virtual e a sociabilidade, tão importantes no período da adolescência, eles também viram porta aberta para a exposição da intimidade, podendo tornar públicos alguns aspectos que deveriam ser preservados pelos seus usuários (SPIZZIRRI, 2008).

Agora, faz-se importante voltarmos nossa atenção para o contexto em que se encontram os resultados dessas modificações, um contexto capitalista. O capitalismo fortaleceu-se em grande parte através do bio-poder (FOUCAULT, 1988), que preconizava a inserção dos corpos no aparelho de produção de forma controlada e, paralelamente, depositava atenção sobre o ajustamento dos fenômenos de população aos processos econômicos. Esse sistema desejava fortalecer a capacidade produtiva, as aptidões, a vida em geral, mas não podia permitir que essa força ultrapassasse o poder de sujeitamento das pessoas. Era preciso que a população fosse útil e forte, porém dócil, obediente e regulada. As instituições (família, exército, Estado, escola, polícia, medicina individual ou administração das coletividades) desempenhavam um papel essencial, a partir do momento em que garantiam a manutenção das relações de produção e também agiam no nível dos processos econômicos, servindo como fatores de segregação e hierarquização da população. Desse modo, garantiam-se as relações de dominação e os efeitos da hegemonia, como trazido por Foucault: 


\section{SEMINÁRIO DE PESQUISA EM CIÊNCIAS HUMANAS - SEPECH \\ Humanidades, Estado e desafios didático-científicos \\ Londrina, 27 a 29 de julho de 2016}

o ajustamento da acumulação dos homens à do capital, a articulação do crescimento dos grupos humanos à expansão das forças produtivas e a repartição diferencial do lucro foram, em parte, tornados possíveis pelo exercício do bio-poder com suas formas e procedimentos múltiplos. $\mathrm{O}$ investimento sobre o corpo vivo, sua valorização e a gestão distributiva de suas forças foram indispensáveis naquele momento (FOUCAULT, 1988, p.133).

O poder agora não lidava apenas com o sujeito de direito, mas abrangia e se infiltrava pelos aspectos da vida em si. Inclusive, os processos da vida agora eram considerados procedimentos de poder e, como tal, passaram a sofrer tentativas de controle e modificação. O homem passa a compreender-se como uma espécie viva em um mundo vivo, estando passível à ação de fatores que podem afetar sua existência, sua probabilidade de sobrevivência, sua saúde individual e coletiva, etc. Pela primeira vez, o biológico começa a se refletir no âmbito político. A saúde já não é mais uma questão pessoal, mas sim, uma questão de interesse das instituições de poder, que se encarregam da vida mais do que da ameaça da morte. A bio-política surge proliferando novas técnicas de investimento no corpo, fazendo afirmações sobre a saúde, às maneiras de se alimentar e de morar, as condições de vida e, dentre outros, sobre a sexualidade.

Para Foucault (apud CARVALHO, 2012), a psicologia, bem como as demais ciências humanas, é um "saber-poder", do qual o conhecimento por ela produzido serve de subsídio para o dispositivo disciplinar ao atuar na produção de um humano que é dócil e útil, correspondendo à demanda de formação social do período capitalista. Esse fato merece destaque ao relembrarmos que atualmente estamos entrando numa sociedade de controle, que não funciona mais a base do confinamento, mas sim através de um controle que é continuado e uma comunicação que é feita de forma instantânea. Foucault (apud CARVALHO, 2012) também ressalta que a psicologia exerce uma vigilância especializada, ao separar o que é normal do patológico, e observando sua ocorrência no meio social. A questão é que agora esse procedimento ocorre de forma generalizada, indo para além dos muros das instituições (clínica, prisões e etc.), e operando a "céu aberto". Ao sair dos limites arquitetônicos desses espaços então destinados para esses tipos de atendimento, a psicologia começa a trabalhar através de uma normalização preventiva, difundindo procedimentos preventivos que atingem grupos antes mesmo da identificação dos casos a serem tratados (CARVALHO, 2012).

A psicologia, ao ser amplamente divulgada em suas vertentes clínicas terapêuticas e preventivas, acaba por produzir muitos efeitos em escala populacional: o indivíduo que até então se relacionava apenas com seus familiares, passa a falar de modo desimpedido de sua vida privada, passa a "confessar", como diria Donzelot (CARVALHO, 2012). A confissão já ocorria anterior ao trabalho do psicólogo. Inicialmente, tratava-se da confissão religiosa ao padre, que ressaltava a importância do relato do ato sexual em si, podendo esse oscilar entre práticas lícitas e ilícitas. A partir da Contrarreforma, o conteúdo da confissão começou a ter sua temática alterada gradativamente, passando a abranger também pensamentos, desejos, imaginações voluptuosas, impondo regras meticulosas no exame de si mesmo e atribuindo maior importância. O sexo devia ser minunciosamente investigado, em suas mínimas particularidades, tudo havia de ser dito. Houve então um deslocamento da descrição das experiências para a inquietação do desejo, transitando da relação com o outro para a 


\section{SEMINÁRIO DE PESQUISA EM CIÊNCIAS HUMANAS - SEPECH \\ Humanidades, Estado e desafios didático-científicos \\ Londrina, 27 a 29 de julho de 2016}

relação consigo mesmo. O individuo não é apenas decifrado através da confissão, pelo contrário, ele se constitui ao realizar um exame de si mesmo e modifica-se no ato de contar suas intimidades a alguém. Dessa forma, afirma-se que não há um sujeito a priori a ser desvendado, mas sim, há uma produção no próprio ato discursivo. A confissão continuou através do século XVIII, com uma forma especificamente moderna e ocidental de relatar o sexo, de maneira mais científica, através do imperativo clínico ao se falar com o médico, então substituto do padre. A confissão não estava mais em posse exclusiva da religião, mas passou a percorrer também a medicina, a psiquiatria e a psicologia, inicialmente através da psicanálise (VAHLE; SANTOS, 2004). Ao adentrar o campo da psicologia, a confissão encontrou-se livre de análise moral, ou diagnóstica:

A técnica 'psi', não incrimina uma pessoa em particular, nem um comportamento errôneo, mas sim as relações estabelecidas no interior da família e as representações mentais inconscientes de seus membros. Ela não pratica a injunção de mudar de normas, mas sim a incitação a um reequilíbrio das atitudes, em nome de seus efeitos sobre os outros membros (DONZELOT, 1986, p. 192).

Por isso, a vinculação dos conhecimentos da psicologia, de forma generalizada pelos meios de comunicação, pode ser uma prática questionável. O ingresso das práticas discursivas confessionais nos meios de comunicação foi de essencial importância para sua difusão e reprodução pela massa. As práticas discursivas confessionais passam a ser neutralizadas, depois de entrarem na família através do rádio e da TV, o que fez com que os pais se "rendessem" a essas orientações vindas de fora, e acabaram por permeabilizarem a família, que deixa de ser tão resistente à discussões sobre a sexualidade, por exemplo.

Qual seria então o atual estado em que se encontra a instituição familiar? Ou melhor, será é possível afirmar que ela ainda existe/persiste? Quais seriam os efeitos dessa desestruturação na vida do adolescente e sua relação com as mídias?

\section{MATERIAL E MÉTODOS}

Essa pesquisa foi realizada através de um levantamento bibliográfico com materiais de diversos autores que se dedicaram a estudar os assuntos aqui abordados.

\section{RESULTADO E DISCUSSÃO}

Como se pôde observar, a família vem se transformando aceleradamente em função das diversas mudanças sociais. Para Ariès, ela se caracterizava e se definia pelo fechamento em si, pelo cuidado com o que era sigiloso e privado, e pela demarcação clara entre o que era destinado ao íntimo, e o que era passível de ser exposto publicamente.

Com o advento da escola e a introdução do ensino, a família sente a incidência de uma primeira interferência. Agora, a escola aparecia com a proposta de um cronograma com normas e atividades estabelecidas que afirmavam acompanhar o 


\section{SEMINÁRIO DE PESQUISA EM CIÊNCIAS HUMANAS - SEPECH \\ Humanidades, Estado e desafios didático-científicos \\ Londrina, 27 a 29 de julho de 2016}

desenvolvimento da criança e a preparavam gradativamente para a vida adulta. A cientificidade da pedagogia passou a competir com os conhecimentos dos pais, em relação a que rumo dar na criação de seus filhos e preparação para a vida. Além disso, a escola passou a externar do núcleo familiar alguns assuntos que antes eram discutidos apenas dentro de casa, como o sexo, por exemplo.

Paralelamente a isso, tem-se o ato confessional, iniciado na igreja, onde os "pecadores" deveriam contar ao padre tudo aquilo que tinham feito tendo em troca a promessa de perdão divino. Posteriormente, a medicina também faria uso da confissão, com o objetivo de levantar dados para conhecer de maneira mais aprofundada a vida íntima de seu paciente, para fins diagnósticos. Por fim, a psicologia aparece também trabalhando com a confissão, ensinando a sociedade a falar sobre seus problemas com alguém externo à família, mesmo sem lidar com esse conteúdo de forma moralista ou asséptica. Além desse novo movimento, a novidade da psicologia também provocava certa curiosidade, que estimulava o paciente não a falar somente com seu terapeuta, mas estender a confissão à quem perguntasse sobre o que acontecia dentro dos limites da clínica.

No entanto, de qualquer maneira, esse percurso trouxe consequências. O psicólogo, através dos relatos obtidos em seu atendimento clínico e seus estudos sobre o comportamento humano, foi construindo uma imagem do que seria anormal, no que diz respeito à saúde mental, elaborando um modelo do que seria aceito ou não como forma de existência humana, baseando-se em seus "conhecimentos científicos", seu "saberpoder". Com o tempo, a psicologia passou a evidenciar menos os comportamentos "anormais", e buscou descrever e impor o modelo do que considerava "normal".

Outro artifício que rompeu a barreira construída em torno do familiar foram as mídias. No início, o rádio e a TV eram produtos de luxo, altamente tecnológicos, acessados apenas por uma minoria privilegiada. Porém, com a popularização desses equipamentos, eles foram se alastrando de tal maneira nos espaços, que rapidamente eram encontrados nos comércios, nas áreas comuns e, principalmente, dentro de casa, no ninho da família. A princípio, os pais até conseguiam regular o período de uso e o conteúdo assistido por seus filhos, mas com o tempo, o costume de assistir à TV, ouvir o rádio ou acessar a internet foi se tornando banal, e o controle foi afrouxado. Assim, tornou-se difícil filtrar o que chegava até as crianças e aos adolescentes da família, que recebiam as mais diversas informações entregues de bandeja na sala de estar. Bem como fez-se igualmente desafiador controlar o que elas produziam e disponibilizavam na internet.

Porém, os conteúdos foram evoluindo de maneira que extrapolaram o entretenimento, e passaram a abranger também aspectos relacionados ao funcionamento da sociedade, da família, dos sujeitos. O psicólogo, dentre outros "detentores do conhecimento" foi convidado a falar por esse canal e passou a espalhar por ali dados que até então eram explicitados de maneira direcionada ao indivíduo, dentro dos limites da clínica. Dessa forma, o modelo do que era considerado "normal" passou a atingir de forma homogênea uma massa heterogênea. A população passou a ter acesso ao que era considerado saudável, ideal, perfeito, e buscou se adaptar a essas instruções provindas de um saber-poder. A sociedade recebeu mais um incentivo rumo à normalização.

Normalização essa que é característica do biopoder. A mídia, a escola e várias outras instituições de poder passam a intervir de forma corretiva, traçando previamente o caminho que deve ser percorrido, baseados em parâmetros que visam medir, avaliar e 


\section{SEMINÁRIO DE PESQUISA EM CIÊNCIAS HUMANAS - SEPECH \\ Humanidades, Estado e desafios didático-científicos \\ Londrina, 27 a 29 de julho de 2016}

acompanhar o desenvolvimento e desempenho dos homens. O poder disciplinar passa a substituir o papel da família a partir do momento que bombardeia esse núcleo com informações provindas de várias direções sobre como eles devem proceder, como devem agir, como devem educar e se cuidar.

Os adolescentes, frutos dessas famílias de poder descentralizado, estariam então sendo indiretamente incentivados pelos mecanismos do biopoder a deslocar aquilo que era considerado privado para o espaço público, permitindo o acesso às suas informações pessoais e ao controle das instituições de poder. Esse movimento evidenciaria o enfraquecimento do exercício de poder de forma hierárquica e vertical, antes executado pela família, e seu deslocamento para o poder que se espalha pelo espaço público, que observa esse corpo de diferentes lugares e se encarrega dele. A exposição dos adolescentes em redes sociais por vontade própria mostra o resultado desse novo modo de agir, como se dissessem "Meu corpo não é sexualizado? Pois o recebam assim então", fruto de toda essa liberdade que a sexualidade foi adquirindo ao longo dos anos, a partir do momento em que conseguiu romper as barreiras do muro que circundava a família, a privacidade, o íntimo. É pertinente até mesmo afirmar que isso se dá como forma de resistência, ao assumirem o que foi feito deles, e devolverem à sociedade a responsabilidade sobre isso, que agora não se apoia apenas sobre a família, mas em todas as instituições que cruzaram o caminho desse jovem em sua vida.

\section{CONCLUSÃO}

No fim, o que fica é a questão: Qual a relação entre a instituição familiar e essa exposição de fotos íntimas dos adolescentes nas redes sociais? Para Ariès, como visto anteriormente, a família se sustentava através de seu fechamento em si, garantindo assim seus papéis e hierarquia de poder, características essas inexistentes nos dias de hoje. As instituições permearam de forma abrupta os limites do núcleo familiar, enfraquecendo o que estava posto até então. Estaríamos assistindo um esvaziamento da formatação familiar em prol do coletivo? Seria essa uma instituição obsoleta? Como conclusão, ao que tudo indica, a família seria uma estrutura ultrapassada, que sucumbiu ao biopoder e acabou deslocando o que até então era de seu controle para os espaços coletivos. Dessa forma, os adolescentes não tem mais a cobrança de antigamente, característica dos pais de, dentre outras coisas, manter o que é privado separado do que é público, e se expõem de maneira explícita como resultado das manobras do biopoder. Além disso, assumem o que foi feito com seu corpo, que agora é reconhecido como sexualizado e devolvem isso à sociedade como forma de resistência.

\section{REFERÊNCIAS}

ARIÈS, P. História Social da criança e da família. Trad. Dora Flaksman. São Paulo: Brasiliense, 1986.

BUCKINGHAM, D. Crescer na Era das Mídias: após a morte da infância. Trad. de Gilka Girardello e Isabel Orofino. Florianópolis. 2006. 


\section{SEMINÁRIO DE PESQUISA EM CIÊNCIAS HUMANAS - SEPECH \\ Humanidades, Estado e desafios didático-científicos \\ Londrina, 27 a 29 de julho de 2016}

DE CARVALHO, P.R.; La Práctica Profesional de la Psicología en la Sociedad de Control. FERMENTUM Mérida, Venezuela, año 22, n 65, p. 289-302, dez. 2012.

DONZELOT, J. A polícia das famílias. Tradução de M. T. Costa Albuquerque. Rio de Janeiro: Graal, 1986.

FOULCAULT, M. História da Sexuliadade I: A vontade de saber, trad Maria Thereza da Costa Albuquerque e J. A. Guilhon Albuquerque. Rio de Janeiro, Edições Graal, 1988.

GUZZI, D. Diálogo, configurações de privacidade e compartilhamento: aja, não seja só um espectador. Pesquisa TIC Kids Online Brasil, p. 29-36, 2013.

FONTES, M.R.M. A normalização da sociedade: Uma questão de poder. Inquietude, Goiânia, vol.1, n 1, jan/jul - 2010.

REIS, J. R. T. Família, emoção e ideologia. In: LANE, S. T. M.; CODO, W. (Orgs.). Psicologia Social: o homem em movimento. São Paulo: Editora Brasiliense, 1994.

SPIZZIRRI, R.C.P. O uso da internet na adolescência: aspectos relativos às relações familiares na pós-modernidade. 2008. 70 f. Tese (Mestrado em Psicologia Social e da Personalidade) - Faculdade de Psicologia, Pontifícia Universidade Católica do Rio Grande do Sul. Porto Alegre. 2008.

VAHLE, M.; SANTOS, E.M. Entre Freud e Foucault: confissão e sexualidade. Clínica \& Cultura, v.III, n. 1, jan-jun 2014, 3-16 